\title{
COMUNICAÇÃO
}

\section{AUMENTO DA PREVALÊNCIA DO VDRL - REAGENTE: RESPOSTA À CAMPANHA DE EDUCAÇÃO CONTRA AIDS?}

\section{J. Tavares-Neto, Meire Ataíde, Luane de Mello e César Morais}

A população na atualidade tem demonstrando atenção crescente com as doenças sexualmente transmissiveis (DST), em particular a sindrome da imunodeficiência adquirida (SIDA)/AIDS.

Esta atenção foi aguçada, ao nosso ver, devido às campanhas de esclarecimentos, em veiculos de comucação de massa, sobre a prevenção da AIDS. Para avaliar esta questão, computamos os pedidos sorologia para sifilis, através do VDRL (Veneral Disease Research Laboratories) ${ }^{1}$, no periodo de 01/01/84 a 31/12/87, de pacientes do Hospital-Escola/Faculdade de Medicina do Triângulo Mineiro de Uberaba, não somente dos internados, como também do ambulatório, inclusive, gestantes e doadores de sangue.

Na Tabela 1, os resultados do VDRL foram dispostos por ano. A variação mensal, dos VDRLreagentes, aparentemente, foi casual; não guardou relação com algumas festividades, como o carnaval ou as regionais. No entanto, ao comparar cada ano entre si, observou-se diferença significativa dos resultados de 1987 aos de $1984\left(\mathrm{X}_{1}^{2}=18,56 \mathrm{p}<0,0005\right), 1985$ $\left(X_{1}^{2}=16,83 \mathrm{p}<0,0005\right)$ e $1986\left(X_{1}^{2}=12,79 \mathrm{p}<\right.$ 0,0005 ). Todavia, as freqüências dos resultados positivos do VDRL de 1984, 1985 e 1986 foram semelhantes $\left(X_{2}^{2}=0,94\right.$ p. $\left.>0,60\right)$, não obstante a freqüência crescente ano a ano. Por isso, comparou-se o conjunto dos resultados ao do ano de 1987 , sendo a diferença altamente significativa $\left(X_{1}^{2}=24,46 \mathrm{p}<\right.$ 0,00001); os individuos VDRL-reagentes de 1987 foram responsáveis por $72,5 \%$ do valor do quiquadrado total.

Este aumento significativo $(8,1 \%)$ do VDRL reagente, em 1987, comparativamente aos anos anteriores $(6,2 \%)$, reforça nossa hipótese inicial, do efeito na comunidade, das campanhas de divulgação sobre AIDS, iniciada de forma sistematizada no segundo semestre de 1986 e com maior ênfase em 1987. Isto provocou maior procura dos pacientes para afastar DST; e conseqüentemente a classe médica, de forma criteriosa, ficou alertada sobre essa hipótese diagnóstica. Pois, o número de pedidos de exames não aumentou em 1987; inclusive, foi inferior ao solicitado em 1985-1986 e mais próximo ao de 1984 .

Em ambulatório especializado, temos observado o número crescente de pacientes que vêm à

Disciplina de Doenças Infecciosas Parasitárias da Faculdade de Medicina do Triângulo Mineiro, Uberaba-MG.

Recebido para publicação em 15/4/88
Tabela 1 - Distribuição dos resultados do VDRL, em Hospital-Geral de 1984-1987, de Uberaba-MG.

\begin{tabular}{lccccc}
\hline & \multicolumn{5}{c}{ VDRL } \\
Exame & Total \\
\cline { 2 - 5 } & \multicolumn{3}{c}{ Reagente } & \multicolumn{3}{c}{ Não-reagente } & \\
\cline { 2 - 5 } & $n$ & $\%$ & $n$ & $\%$ & \\
\hline 1984 & 280 & 5,9 & 4470 & 94,1 & 4750 \\
1985 & 396 & 6,2 & 6041 & 93,8 & 6437 \\
1986 & 370 & 6,4 & 5457 & 93,6 & 5827 \\
1987 & 398 & 8,1 & 4492 & 91,9 & 4890 \\
\hline Total & 1444 & 6,6 & 20460 & 93,4 & 21904 \\
\hline
\end{tabular}

consulta, espontaneamente, para afastar DST, especialmente, a presença de anticorpos contra o HIV (vírus da imunodeficiência humana) ou referenciados por facultativos. Outro aspecto importante é que a população relaciona, muito freqüente, AIDS e "manchas na pele", como causa e efeito; talvez pelo conhecimento distorcido de que a infecção pelo HIV sempre evolui para o sarcoma de Kaposi ou infecções oportunistas de pele e/ou tecido celular subcutâneo. Esta parece ser a explicação para o aumento da freqüência de casos de sífilis secundária, com lesões do tegumento, diagnosticados em nosso serviço ambulatorial.

Portanto, este resultado, e de outros Autores, podem servir como indicador do efeito, na população, de campanhas para esclarecimento sobre AIDS. Investigações semelhantes devem ser realizadas em outros serviços, tanto públicos como privados, com o objetivo, inclusive, de avaliar o custo/benefício dessas campanhas de divulgação. Em Londres, por exemplo, Gellan \& Ison ${ }^{2}$ observaram queda do número de culturas, positivas para Neisseria gonorrhoea a partir de 1985 (6,2\%; sendo em 1986 de 4,6\%), quando anteriormente, $1983-84$, era em torno de $8,0 \%$. Von Krogh e cols ${ }^{4}$, em Estocolmo, referiram situação semelhante; por volta de 1982 o número de casos de sifilis aumentou na população e, principalmente, entre os homens homossexuais e bissexuais. Também, Polakoff ${ }^{3}$ referiu o aumento da incidência de casos de hepatite B em 1984 e diminuição a partir de 1985.

Nesse sentido, com a divulgação de filmes educativos pela televisão, aumentou o número de escolas, fábricas e associações interessadas em palestras sobre AIDS para seus membros. Munhoz, Tavares-Neto \& Higino (dados não publicados) em 
inquérito com 414 escolares de Uberaba, dos diversos extratos sócio-econômicos, verificaram ser de razoáveis a bons os conhecimentos sobre AIDS (transmissão e prevenção); ao contrário das respostas ferentes à sexualidade humana e outras doenças sexualmente transmissiveis, demonstrando conhecimentos restritos, preconceituosos ou distorcidos.

\section{REFERÊNCIAS BIBLIOGRÁFICAS}

1. Bracero L, Wormser GP, Bottone EJ. Serologic tests for syphilis: a guide to interpretation in various stages of disease. Mount Sinai Journal de Medicina 46:289-192, 1979.

2. Gellan MCA, Ison CA. Declining incidence of gonorrhoea in London: a response to fear of AIDS? Lancet 2:920, 1986.

3. Polakoff S. Decrease in acute hepatitis B incidence in England and Wales in 1985-1986. Lancet 1:380, 1987.

4. Von Krogh H, Hellström L, Böttiger M. Declining incidence of syphilis among homossexual men in Stockholm. Lancet. 2:920, 1986. 